\title{
YRG CARE base model report: Integrated prevention, care, and support services
}

Christopher Castle

Follow this and additional works at: https://knowledgecommons.popcouncil.org/departments_sbsr-hiv How does access to this work benefit you? Let us know!

\section{Recommended Citation}

Castle, Christopher. 2003. "YRG CARE base model report: Integrated prevention, care, and support services," Horizons Project Report. Washington, DC: Population Council. 


\section{YRG CARE \\ Base Model Report}

\section{Integrated Prevention, Care, and Support Services}

A document produced as part of the study,

"Scaling-up affordable and appropriate care and support services for people living with HIV/AIDS in South India, " conducted by

YRG CARE, Horizons, and the International HIV/AIDS Alliance

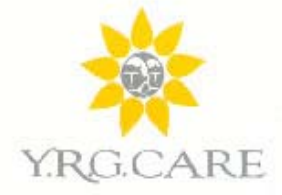

$$
\text { Hgrizons }
$$

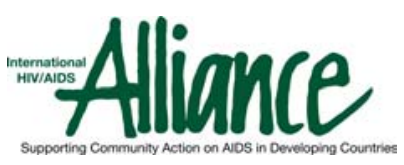


USAID This study was supported by the Horizons Program, which is implemented by the Population Council in collaboration with the International Center for Research on Women, International HIVIAIDS Alliance, Program for Appropriate Technology in Health, Tulane University, Family

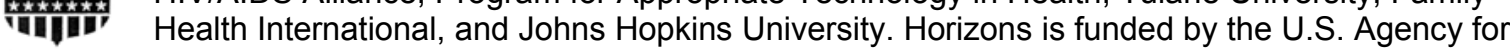
International Development, under the terms of HRN-A-00-97-00012-00. The opinions expressed herein are those of the authors and do not necessarily reflect the views of the U.S. Agency for International Development.

Published in May 2003.

\footnotetext{
(P. Population Council

The Population Council is an international, nonprofit, nongovernmental institution that seeks to improve the wellbeing and reproductive health of current and future generations around the world and to help achieve a humane, equitable, and sustainable balance between people and resources. The Council conducts biomedical, social science, and public health research and helps build research capacities in developing countries. Established in 1952, the Council is governed by an international board of trustees. Its New York headquarters supports a global network of regional and country offices.
}

Copyright (C) 2003 The Population Council Inc. 


\section{Acknowledgments}

Many people contributed to the production of this document. Mr. Gladston Xavier worked on many of the early drafts in his capacity as research associate for the Horizons study based at YRG CARE. Dr. Suniti Solomon, principal investigator for the study and director of YRG CARE, provided much of the organizational history and information used throughout the document. Mr. A.K. Ganesh also made important contributions, as did doctors Purnima Madhivanan and N.

Kumarasamy. We also thank the project/research coordinator, Mr. Benjamin Franklin, his team, and the staff of YRG CARE for their ideas and perspective. Chris Castle, Horizons

Project/International HIVIAIDS Alliance, produced the final version of this document.

We also express our appreciation to Dr. Celine Costello-Daly (Horizons, New Delhi) and Dr. Rick Homan (Family Health International's Health Economics Unit) for reviewing an earlier draft. Thanks also to Ms. Eva Roca (Horizons), who assisted with the re-formatting of the figures contained in this publication. 


\section{Contents}

1. Introduction and purpose of this document 1

2. The genesis of YRG CARE and overview 2

3. Evolution of the model and services 4

3.1 Prevention 5

3.2 Integrated continuum of care and support 6

$\begin{array}{ll}\text { 3.2.1 Psychosocial support and counseling } & 6\end{array}$

3.2.1.1 Pretest counseling $\quad 7$

3.2.1.2 Post-test counseling $\quad 8$

$\begin{array}{ll}3.2 .1 .3 \text { Nutritional counseling } & 8\end{array}$

3.2.1.4 Couple counseling 9

3.2.1.5 Family counseling 9

3.2.1.6 Antenatal counseling 9

3.2.1.7 Counseling for children $\quad 9$

3.2.1.8 HIV antibody testing as part of voluntary counseling and testing 10

3.2.2 Medical care 12

3.2.2.1 Initial examination and diagnosis $\quad 14$

3.2.2.2 Outpatient care 14

$\begin{array}{ll}\text { 3.2.2.3 Day care } & 14\end{array}$

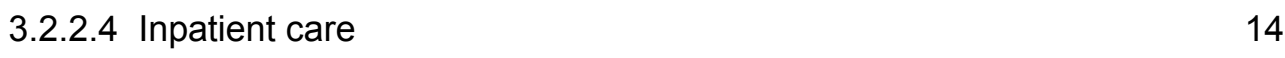

3.2.2.5 The Women's Clinic 14

3.2.2.6 Pediatric care 15

$\begin{array}{ll}3.2 .2 .7 \text { Home care } & 15\end{array}$

3.2.2.8 Referral 15

3.3 Other services and activities 15

$\begin{array}{ll}\text { 3.3.1 Support services } & 15\end{array}$

3.3.2 Policy, advocacy, and networking 16

$\begin{array}{ll}\text { 3.3.3 Training and support services offered } & 16\end{array}$

3.3.4 Staff development and continuing education at YRG CARE 16

$\begin{array}{ll}\text { 3.3.5 Publications and research } & 16\end{array}$

$\begin{array}{ll}\text { 3.3.6 Resource mobilization and sustainability } & 17\end{array}$

$\begin{array}{ll}\text { 3.3.7 Project development and management } & 18\end{array}$

4. References 20 


\section{Introduction and purpose of this document}

In September 1999, YRG CARE embarked on a research project in collaboration with the Horizons Program (funded by the U.S. Agency for International Development) and the International HIVIAIDS Alliance, entitled Scaling up affordable and appropriate care and support services for people living with HIVIAIDS in South India. ${ }^{1}$ The study has two goals. The first is to better understand the affordability and appropriateness of an integrated care and support model in an emerging epidemic situation to meet the needs of people living with HIVIAIDS (PLHA) and to improve their quality of life. A second goal is to examine the process and costs of scaling up this model through a strategy of concept replication in varied settings in South India. A critical step toward achieving both of these goals is to thoroughly document the conceptual and operational model of integrated prevention, care, and support used by YRG CARE, also described by the study partners as the "base model," and the first of seven research objectives. ${ }^{2}$

The task of completing documentation of the YRG CARE base model has been greatly facilitated by the high quality and number of publications produced by the organization since its inception in 1993 (see References, section IV). These contain a wealth of information describing the development of the organization, its philosophy, and its core values. However, there was a need to synthesize the data from these published sources into one concise reference document and also to enrich that information with more of a historical perspective on YRG CARE's founding director and staff, including lessons learned and insights into how the range of HIVIAIDS services developed over time This document has undergone several drafts, each reviewed and revised internally and with the support of Horizons staff. Through the use of individual interviews and open-ended questions, an estimated 90 percent or more of YRG CARE staff were consulted during the documentation of this base model for information and for their ideas, opinions, and perspectives.

One final note about the base model is that YRG CARE does not view it as static and unchanging. Indeed, an important core value of the organization is that it continually strives to learn as it develops and seeks to fulfill its mission of responding to the care and support needs of people living with HIV and AIDS (PLHA). The results of the research, therefore, should provide new insights and lessons that can be used by YRG CARE to refine and improve its efficiency in meeting the needs of increasing numbers of PLHA. Sharing lessons from the YRG CARE experience should also inspire and support the work of others concerned with the welfare and needs of PLHA and their families and communities.

\footnotetext{
${ }^{1}$ A full description of the study protocol is contained in the Horizons proposal, Scaling up affordable and appropriate care and support services for people living with HIVIAIDS in South India, 6 August 1999, 56 pages.

${ }^{2}$ Page 8, objective 1, Horizons study proposal, 6 August 1999.
} 


\section{The genesis of YRG CARE and overview}

The first case of HIV infection was documented in India at the Madras Medical College by a laboratory team headed by Dr. Suniti Solomon in May $1986 .{ }^{3}$ This discovery generated a great deal of denial throughout Indian society, a response of fear, disbelief, overreaction, hostility, blame, and a lack of compassion for those who were seropositive.

Later in the same year, the Indian Council for Medical Research (ICMR) funded the Madras Medical College to establish an AIDS Research Cell to conduct sentinel surveillance. The results were published as an article in the International Journal of STDs and AIDS, ${ }^{4}$ indicating a ten-fold rise in HIV infections among STD clinic attendees and a two-fold increase among antenatal women and voluntary blood donors between 1989 to 1993. Five percent of the first 100 cases of HIV at the Madras Medical College surveillance centre were students.

The steady drop in the age of people with HIV infection, as seen in the walk-in program at the laboratory of Dr. Suniti Solomon, convinced her of the urgency of establishing an outreach education program in the voluntary sector. Thus the YRG Centre for AIDS Research and Education (YRG CARE) was formed in 1993 within the Y.R. Gaitonde Medical, Educational, and Research Foundation. ${ }^{5}$ The activities of YRG CARE gradually expanded from its initial focus on adolescents and young adults to include training of trainers, the production and dissemination of educational materials, the establishment of a continuum of care and support, consulting services in the area of sexual health, program management, and clinical and social research.

\section{Vision, mission, and objectives}

YRG CARE's goal is that people living with HIV and AIDS and their families are able to live with dignity and that there is no further transmission of HIV. The organization describes its mission as responding to the needs of the people who are not receiving care and support or education andinformation about HIV.

The objectives of YRG CARE have evolved to include:

- Building awareness of HIV infection and promote safe and responsible behavior in the community.

- Providing all people with HIV access to a non-coercive and non-stigmatized counseling, testing, and a continuum of care.

- Developing YRG CARE's human resources, physical infrastructure, and organizational systems.

- Advocating for individual rights and polices for a non-judgmental supportive environment for the people living with HIV and AIDS and people affected by the epidemic.

As of the year 2000, YRG CARE reports providing comprehensive services for over 2,500 PLHA and their families. ${ }^{6}$ YRG CARE professionals at the Voluntary Health Services Campus in Chennai staff a 24-bed inpatient care facility, where day care services, nutritional counseling, a family support service, and a subsidized pharmacy program are also provided. A team of doctors and nurses also provide a home care service.

\footnotetext{
${ }^{3}$ Page 5, Pragnya: from consciousness to awareness, Rashmi Pachauri Rajan, October 1992.

${ }^{4}$ As reported in Pragnya: from consciousness to awareness, Rashmi Pachauri Rajan, October 1992.

${ }^{5}$ See the organizational structure contained in the appendix.

${ }^{6}$ Described in HIV Disease in India: a colour guide, 2000, page 117.
} 
The premise on which the YRG CARE integrated care model functions is as follows: ${ }^{7}$

- Deliver a continuum of care and significant symptom control at low costs.

- Promote early detection of HIV.

- Focus on the effective treatment of common opportunistic infections.

- Reduce mother-to-child transmission wherever possible.

- Provide antiretroviral treatment to those who can afford it.

- Offer a non-stigmatizing, caring, and confidential environment to all.

- Enhance the practice of universal precautions at all medical establishments.

YRG CARE's model of integrated care services includes prevention of both HIV infection and related opportunistic infections because their services are founded in prevention, including:

- Prevention education, as typified by their work with schools and young people.

- Prevention of HIV transmission within the families of clients.

- Prevention of opportunistic infection by prophylactic treatment and counseling about nutrition and healthy lifestyle.

Key features of the YRG CARE base model include the following:

- The attitudes of clinicians and other carers are positive, putting the needs of patients and their families at the forefront of service planning and delivery.

- Prevention and cure of opportunistic infections, symptom control and psychosocial support are affordable and accessible to all patients and their families.

- Confidentiality and patient concerns are respected.

- Patients and their families are given information about HIV infection, treatments, and prevention of HIV infection and opportunistic infections.

- Referral is offered where there are gaps in services available and whenever patients request it.

- Individual, couple, and family counseling are available, as well as a voluntary counseling and testing service, in operation since January 1994.

- When in-patient hospitalization is not needed, clients can receive services through YRG CARE's outpatient day care, in-patient hospital stays, or home visits.

- A qualified nutritionist is on hand to provide information about the nutritional needs of PLHA. YRG CARE's hospital at VHS includes a dental clinic for the treatment of oral manifestations.

- Referrals are made for surgery and invasive procedures, including, for example, referral to the regional eye institute.

- Staff value their ability to provide holistic and comprehensive support to their clients. Because clients are routinely turned away from other medical and social service institutions due to suspected HIV status, the services, appropriate care, and supportive environment provided by YRG CARE are all the more meaningful and important. ${ }^{8}$

- One of the strengths of the YRG CARE model is its proven track record in attracting local sources of financial and other support. Staff work constantly on mobilizing support from roundtable business groups, previous clients, local industry, and state government departments.

- This close attention to sustainability and financial management capacity is a core element of the model that is being scaled up, and one of the anticipated training workshops is devoted to this theme. With support from the International HIVIAIDS Alliance, YRG CARE staff will also provide additional one-to-one technical support to scale up partners on proposal development, external relations, and related skills.

\footnotetext{
${ }^{7}$ Described in HIV Disease in India: a colour guide, 2000, page 117.

${ }^{8}$ Trip report, International HIVIAIDS Alliance, Mike Bailey and Anne Scott, November 1997.
} 


\section{Evolution of the model and services}

In 1993, YRG CARE established perhaps India's first anonymous walk-in clinic for HIV in the voluntary sector. Since its inception, this clinic has been offering voluntary and confidential HIV testing, together with counseling.

From this beginning, YRG CARE has incrementally developed new services (see box with milestones below). The at which the organization has managed to add new services has depended on a number of factors, including its ability to mobilize resources (both in-kind and financial), recruit new staff and build their capacity, and develop organizational systems for managing and strategically planning for growth.

\section{Milestones of YRG CARE relating to care and support services}

Nov 1993 Voluntary testing for HIV antibodies offered together with counseling

Nov 1993 YRG CARE begins to function as the confirmation center (Western Blot) for several hospitals and laboratories in Tamil Nadu

Feb 1994 Twice a week evening HIVISTD clinic inaugurated with voluntary services provided by physicians

Jun 1994 HIVISTD clinic strengthened, open on evenings, Monday through Sunday

Dec 1994 Day care for PLHA (Saturday afternoons) dedicated; home visits undertaken on call

Nov 1995 Full-time physician and nurse recruited; HIVISTD clinic and day care for PLHA extended to other working days of the week (10:00 - 18:00)

Dec 1995 Peripheral hospital for convalescing patients dedicated at Kottivakkam, Madras; second physician joins; home care strengthened

Dec 1995 Consortium of Consultants formed

Feb 1996 Dr. Suniti Solomon joins Voluntary Health Service Society as their Honorary Consultant for HIV medicine

Feb 1996 Voluntary Health Services - YRG CARE begins to admit and manage patients

Dec 1996 Established the "VHS - YRG CARE Medical Center" on the VHS campus with a 16bed in-patient facility

Dec 1997 In-patient facility expanded to include a fully furnished day care; functional diet centre and drug and diagnostic support program launched

Apr 1998 Women and children's ward established with 8 beds; Women's Reproductive Tract Infection (RTI) clinic also started

Oct 1998 Special pediatric outpatient (once a month) initiated

Aug 1999 Family Counseling Centre established

Dec 1999 Scale-up project with four partner sites in South India started

Dec 2000 VHS-YRG CARE Infectious Diseases Laboratory established 


\subsection{Prevention}

Before YRG CARE was able to officially launch its prevention activities in 1993, it was necessary to address the severe stigma surrounding HIVIAIDS that made it difficult to even secure premises for an office. This required making an effort to raise awareness about HIV with landlords and neighbors in the area where office space was eventually located.

Initially, prevention activities were primarily carried out in educational institutions out of recognition that HIV increasingly threatens young people who are disadvantaged by limited access to prevention information. ${ }^{9}$ In the beginning, there was considerable opposition from the heads of the educational institutions to start the program, as they believed that talking about sex was taboo. Therefore, YRG CARE adopted a "top down" approach starting with the Education Ministry, the Education Secretary, and the Director of School and College Education to gain permission for prevention activities. This was followed by advocacy with the educational institutions themselves about the need for preventive education.

To gain entry into the educational institutions, YRG CARE organized a half-day workshop on prevention for the heads of the educational institutions in the city of Chennai with the assistance of the Rotary Club-Park Town. Forty institutions participated in the program, which was highly successful in opening the doors for the involvement of 78 school principals. This eventually enabled YRG CARE to widen the scope to include direct work with students, which uncovered an additional set of challenges such as opposition on the part of some parents and school administrators to the demonstration of condoms, dispelling myths, and misconceptions about sex and sexuality.

\begin{tabular}{|l|l|}
\hline \multicolumn{2}{|l|}{ Students sensitized through the prevention program, 1993-1999 } \\
\hline Schools: & Colleges: \\
\hline Number of presentations: 94 & Number of presentations: 65 \\
\hline Number of students covered: 44,826 & Number of students covered: 15,2151 \\
\hline
\end{tabular}

When YRG CARE started the prevention program sessions lasted for one hour. However, due to the growing queries of the students and the community, sessions were extended to half a day, then a full day, and eventually to a full 2-day program to allow sufficient time.

The main components of sessions consist of:

- An audiovisual presentation on the basic facts on HIVIAIDS. ${ }^{10}$

- Body mapping.

- Myths and misconceptions about sex and sexuality.

- Prevention, safe sex, safe blood, and safe needles.

- Values and attitudes toward people living with HIVIAIDS.

- Personalizing HIVIAIDS. ${ }^{11}$

- Communication

Today, the overall aim of YRG CARE's prevention service includes much more than just education on how to prevent the transmission of HIV through a range of awareness and intervention programs. It also involves such activities as advocacy, peer education,

\footnotetext{
${ }^{9}$ Research conducted by YRG CARE has indicated that young people who receive sex education are better equipped to delay sexual activity as well as adopt safe behaviors. J. Easter Thamburaj, S.K. Satish Kumar, A. Edwin, A.K. Ganesh, S. Suniti, Students perspective on sex education: a comparative study from Chennai, India, [ThPeD5595], YRG CARE, Chennai, India, Break the Silence, XIII International AIDS Conference 2000.

${ }_{11}^{10}$ See, for example, Let us talk about HIVIAIDS, YRG CARE, slide set and discussion guide.

${ }^{11}$ For example, see the publication Whispers from within: the unheard voices of HIVIAIDS, YRG CARE, 1997.
} 
counseling, training, community mobilization, HIV care and support, information on sex and sexuality, and developing resource materials. Prevention efforts include encouraging adolescents, youth, women, and men to make informed decisions. ${ }^{12}$ Ongoing public education is an important part of the prevention program, and members of the community who request information, education, or training on HIVIAIDS are able to gain access to this service free of charge from YRG CARE. The prevention program has been popular since the beginning of the organization.

At present, three prevention staff who are specially trained to deal with sex and sexuality issues carry out the services. In addition to prevention efforts aimed at students and staff of schools and colleges, YRG CARE provides prevention education programs for industries/factories, for women's groups, NGOs and villages, and reach urban as well as rural people in Tamil Nadu with traditional art forms and other strategies. ${ }^{13}$

YRG CARE consistently monitors and evaluates the prevention program, relying primarily on questionnaires to participants after a program in order to obtain feedback. Responses are studied and suggestions are considered for improving future prevention activities.

\subsection{Integrated continuum of care and support}

The integrated continuum of care and support services provided by YRG CARE can be categorized into the following four domains: psychosocial support and counseling, diagnosis, medical car,e and support services. Each area will be considered in detail.

\subsubsection{Psychosocial support and counseling}

"I felt that one ought not to receive the test results as he or she would receive for any other illness. Therefore I began talking to those who came for a test and this practice evolved into preventive and counseling services." Dr. Suniti Solomon

Based on experience with the prevention programs, YRG CARE found that people were seeking help and needed direction, particularly PLHA and their families, but there was no place for them to obtain this support. It was from this starting point that the counseling services were developed. It was soon learned, for example, that PLHA encounter a number of problems and face many issues as a direct result of their HIV infection. These include loss of self-esteem, recurrent illness, loss of employment or inability to work, and loss of family support. There may also be concerns about infecting one's spouse or unborn children.

Counseling at YRG CARE aims to help families and friends understand the realities of HIV infection. Understanding these facts helps them not only to cope better with HIVIAIDS, but also contributes toward an enabling environment for PLHA. The aim is to help people accept and cope with the knowledge of being HIV-positive, and ultimately to encourage acceptance and support from families and communities. With the consent of the client, YRG CARE

\footnotetext{
12 A module entitled Learning to play safe was developed and translated into four languages to be used for training of trainers on sexuality and HIVIAIDS.

${ }^{13} \mathrm{~A}$ study conducted by YRG CARE showed equally high prevalence of HIV in urban and rural areas of Tamil Nadu and underscored the need for strategies to reach illiterate and rural populations. YRG CARE identified such traditional art forms of rural Tamil Nadu as drama, sculpture, street play, puppetry, and folk songs, and developed a module for artists in the vernacular. This module was used as a reference by the artists, especially to clarify common myths and misconceptions about HIV and sexuality. See L. Mani, J.L. Franklin, A.K. Ganesh, S. Suniti, Reaching rural Tamil Nadu through art forms: a pilot study by YRG CARE, [ThPeD5679], Break the Silence, XIII International AIDS Conference 2000.
} 
extends counseling to the spouse, sexual partners, and relatives based on the concept of shared confidentiality.

The counselors at YRG CARE are recruited by interview, and HIV-positive, asymptomatic women are preferred. Some of the qualities that YRG CARE seeks in counselors are people with a pleasant demeanor, the ability to empathize, comfort with all sexual orientations, no moral judgements, an ability to socialize with people of all social backgrounds, and a willingness to work whenever needed. The counselors are trained in-house for three months and are sent for locally available training. ${ }^{14}$ YRG CARE counselors are trained in the skills of the job, including how to listen to the client, how to ask supportive questions and discuss options, and how to encourage the client to make his or her own informed decisions by providing practical information and suggesting follow-up. The counselor helps the client to pursue realistic solutions to his or her difficulties. Important aspects of counseling that form part of the training include such things as having a non-judgmental attitude and conveying genuineness, patience, emotional maturity, flexibility, unconditional acceptance, consistency and accuracy, confidentiality, and accessibility. ${ }^{15}$

For the period of 1 September 1999 through 31 August 2000, YRG CARE conducted 1,114 counseling sessions. These were provided in the following areas: ${ }^{16}$

- Pretest counseling

- Post-test counseling

- Nutritional counseling

- Follow-up counseling

- Family counseling

- Couple counseling

- Grief counseling

- Terminal counseling

\subsubsection{Pretest counseling}

Pretest counseling is often the first contact between YRG CARE and the client. Counselors ask clients to indicate where they are from and how they heard about YRG CARE. Personal details about the client are obtained, including marital status, level of education achieved, occupation, sexual orientation, sexual practices, condom use, travel, and substance use, as well as information concerning spouses (if applicable) and/or other sexual partners, such as their level of education and occupation. The client's history of tuberculosis, sexually transmitted illnesses, jaundice, vaginal discharge, and receipt of blood or blood products is also recorded. ${ }^{17}$

Informed consent is always acquired before an HIV test where the individual's name is linked to the result. The person's ability to cope with the positive result is assessed. The pretest counseling at YRG CARE ensures that the person understands about HIV and AIDS. Factual information is provided as needed. ${ }^{18}$ The person's possible risk for HIV is assessed, as well as potential implications of a positive, negative, and indeterminate test result, and the window period is clearly explained. The person's ability to cope with a positive result is assessed. A relationship is established as the basis for post-test counseling.

\footnotetext{
${ }^{14}$ For example, training provided by SIAAP in HIV counseling.

${ }^{15}$ Experience gained over the years by YRG CARE in the field of counseling has been consolidated and published in a manual entitled Encounters that help, YRG CARE, 1999.

${ }_{17}^{16}$ Page 17, Encounters that help, YRG CARE, 1999.

${ }^{17}$ Client details are recorded in a specially designed format for pretest counseling.

${ }^{18}$ See AIDS: frequently asked questions, Solomon, S., YRG CARE, 2000.
} 


\subsubsection{Post-test counseling}

If a negative test result is obtained, YRG CARE counselors view counseling as very important. While the client is likely to feel relief, the counselor emphasizes several points. First, because of the window period, a negative result may not mean the absence of infection, and the client might wish to consider returning for a repeat test after three to six months. Second, the counselor discusses HIVIAIDS prevention, providing support to help the client adopt and sustain any new safer practices.

When the result is positive, the counselor makes sure during post-test counseling that the person understands what a positive result means. Key to this is a discussion about how a person feels about being infected. In this exercise, counselors find that patients generally fear that society, family, and friends will not accept them. Support is provided to help the person deal with negative feelings, and plans for the immediate future are discussed. A relationship is established as a basis for future counseling. Appointments are scheduled for medical evaluation and follow-up counseling. The partners are counseled where possible. Referrals are made to local community services where relevant.

\section{Some steps that are adopted in the post-test counseling at YRG CARE:}

- The results are checked if they belong to the client. The results are not given unless permitted by the client's doctor. Care is taken that the results are not given before an approaching weekend, as support services are minimal during the weekend.

- The client is made comfortable and the results are given in a straightforward manner at the start of the session.

- Enough time is given for the result to sink in. There is no attempt made to fill in the silence with unnecessary speech or any explanations. The cue is taken from the client: if it the person appears to need some reassurance or an explanation, then this is offered.

- Counselors remind the client of whom he or she had wanted to tell or talk with after receiving the results. However, the counselor does not insist that this happen.

- Counselors make sure that the person has someone to talk to whenever necessary.

- Written information on the contact numbers is given in case the client wants to get in contact with the counselor again.

- Any unusual emotional response is checked.

- If needed, referrals are made.

\subsubsection{Nutritional counseling}

Clients who have tested positive are referred to YRG CARE's nutritionist, after they see the doctor, for nutritional counseling. Based on a nutritional assessment, which consists of a physical assessment and dietary history of the patient, a qualified nutritionist administers the counseling.

Nutritional counseling differs from person to person, depending to his or her physical condition. The social and economic condition of the client, the type of job he or she works, and hours of work are kept in mind when recommending certain diets and discussing diet plans. Practical information with regard to diet, food habits, and hygiene is stressed. The importance of a balanced diet in delaying the progression of the disease from the asymptomatic stage to the symptomatic stage is emphasized.

This counseling session includes information on the intake of the food fortified with vitamins, protein, fats, minerals, and carbohydrates. The importance of using boiled water is emphasized. Food that is locally available and rich in nutrients is suggested as the best means of retaining strength. Various aspects of diet and drug intake are explained. The use 
of healthy and hygienic food is stressed, taken in the prescribed quantity at regular intervals. ${ }^{19}$ Sessions typically last for about 30 minutes.

\subsubsection{Couple counseling}

People who come for pretest counseling are invited to come back with their partners to facilitate joint decisions prior to testing. If the person decides to go ahead without telling the partner and is found positive, the counselor may suggest that the couple come in together for counseling. This approach to counseling-involving the partner-helps resolve misunderstandings between the couple. The counselor explains the ethical and practical problems that non-disclosure can pose.

Couple counseling provides a safe place to discuss difficult issues, and it makes it easier if the partners have the test at the same time. Partners who are both negative can plan to stay that way through behavior change and mutual faithfulness. Discordant couples are provided with an opportunity to make important choices about reducing the risk of transmission through sexual activity by using safer sex methods, having children, and other related issues.

\subsubsection{Family counseling}

In the Indian family situation, people try to avoid putting a patient in a hospice; hence family members receive information on the patient's situation and are counseled on how to accept the patient at home and how to provide adequate care. YRG CARE has been successful in counseling families and gaining their acceptance that the patient can be cared for at home.

\subsubsection{Antenatal counseling}

As part of the Women's Clinic, antenatal counseling is an important service that is in high demand. It is offered to pregnant women or women wanting to be pregnant, who are either HIV-positive or unaware of their HIV status or the status of their spouse. It facilitates making informed decisions about whether to become pregnant if HIV-infected, whether to take a test before pregnancy, and if pregnant, whether to terminate pregnancy through legally available options.

For those who are already pregnant, counseling also includes discussion about the use of zidovudine where available to reduce the risk of transmitting HIV to the unborn child, and about breastfeeding and other infant feeding options. Where possible and when the woman agrees, it is seen as advantageous to involve her male partner in the counseling sessions. Ideally, YRG CARE believes that women should have counseling available to them before they become pregnant.

\subsubsection{Counseling for children}

Children have special counseling needs, such as dealing with the emotional trauma of seeing their parents become ill or die, confronting discrimination by other children and adults, and coping with emotional worries about the continuing illness of one or both parents or siblings. Older children also need counseling about sexual issues and the avoidance of risk behavior.

Before disclosure, the child is educated about HIVIAIDS. The child is informed that HIVIAIDS is just like any other disease, for example, pneumonia or tuberculosis, and that

${ }^{19}$ See pages 4-7, Dances of the sunflower, YRG CARE, 1998. 
anyone can get it. It is explained that there are no grounds for any discrimination against a person living with HIVIAIDS, and that HIV does not spread through casual contact, so that a person can continue with his or her everyday activity, such as going to school, college or work. Parents are encouraged to listen to the radio or watch TV with the children when programs on HIVIAIDS are broadcast. It is believed that these strategies will help the child to cope better with the disease when it is eventually disclosed.

\subsubsection{HIV antibody testing as part of voluntary counseling and testing}

Following from the success of the prevention programs, YRG CARE experienced a substantial increase in the number of people seeking to know their serostatus, leading the organization to establish its own laboratory for the purpose of HIV antibody testing. HIV testing is considered part of the organization's overall comprehensive prevention, care, and support program.

Qualified, trained, and experienced laboratory technicians perform the tests, and YRG CARE places great importance on ensuring that the HIV testing it conducts is technically sound, appropriate, and accurate. ${ }^{20}$ YRG CARE adheres rigorously to the National AIDS Control Organization (NACO) guidelines on testing.

A sliding scale determines what clientS will be charged, depending on what they can afford. The tests are done On the campus of the VHS-YRG CARE facility, and charges are as follows: ELISA 100 Rs., VDRL 25 Rs., and Western Blot 1,200 Rs. Other tests and their charges include toxoplasmosis 200 Rs., crypto 400 Rs., blood grouping 25 Rs., and TPHA 75 Rs.

In December 2000, YRG CARE inaugurated a state-of-the-art infectious diseases laboratory, established with financial support from the NIMH and Johns Hopkins University (USA). When this laboratory is fully operational, it will be capable of handling a full range of laboratory diagnosis, including CD4 counts, PCR, and viral load testing. Before the YRG CARE lab opened, YRG CARE shipped samples to a laboratory in Ranbaxy, Mumbai, for these tests.

${ }^{20}$ Evaluated by Brown University, USA. 
Figure 1: Number of walk-in clients for HIV testing received by YRG CARE, 1994-1999.

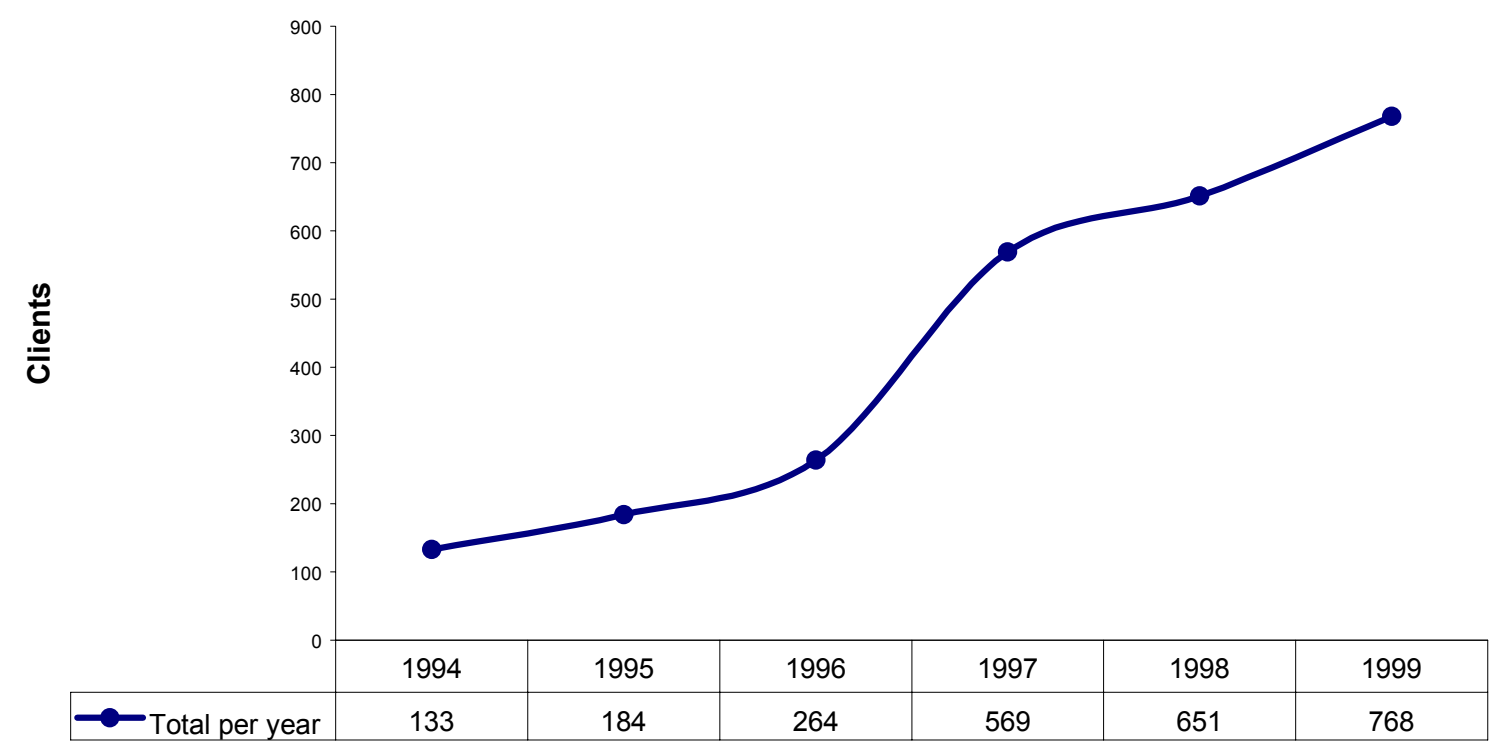

Figure 2: New HIV infections diagnosed at YRG CARE during VCT, 1994-1999

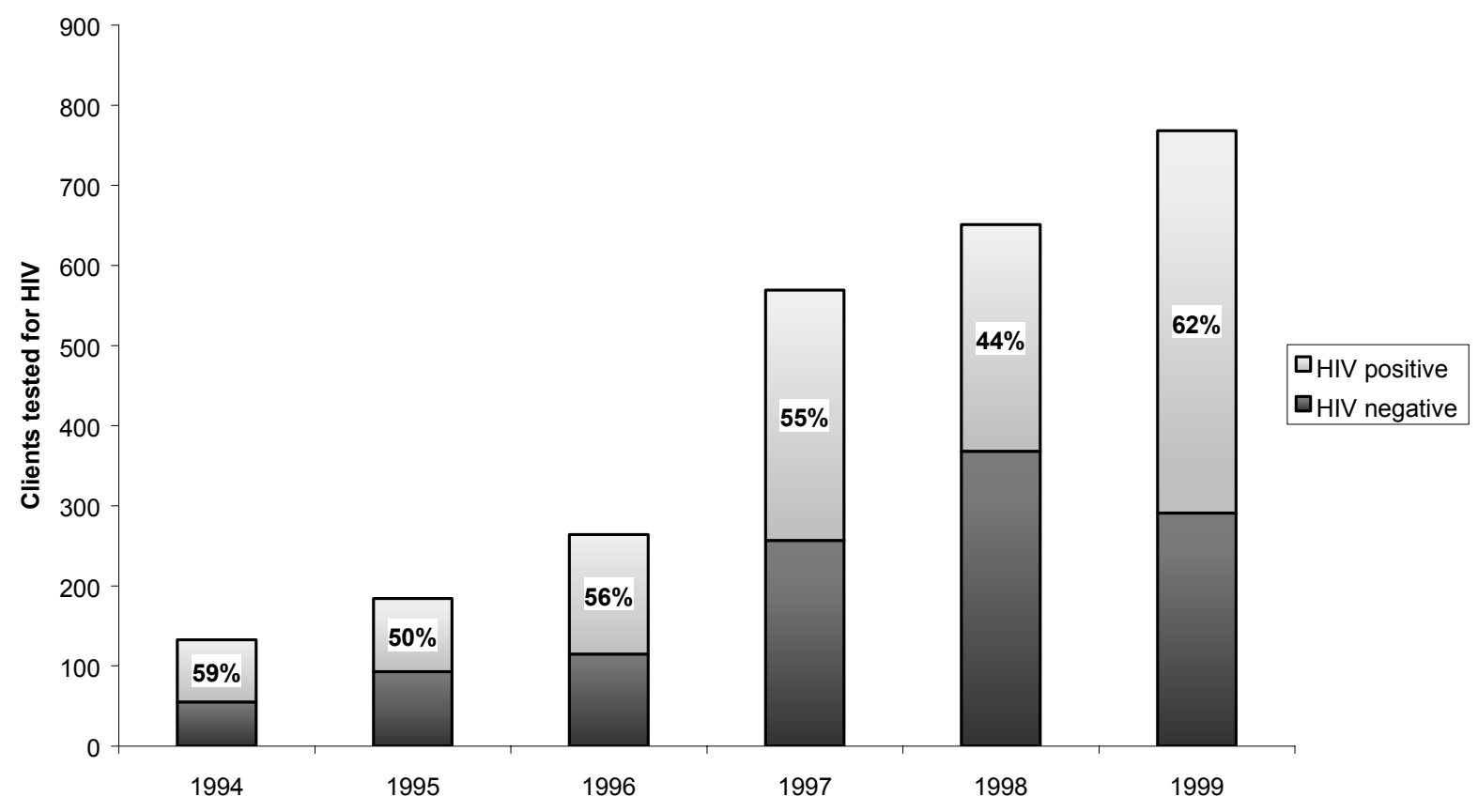


Figure 3: Occupational categories of clients benefiting from YRG CARE

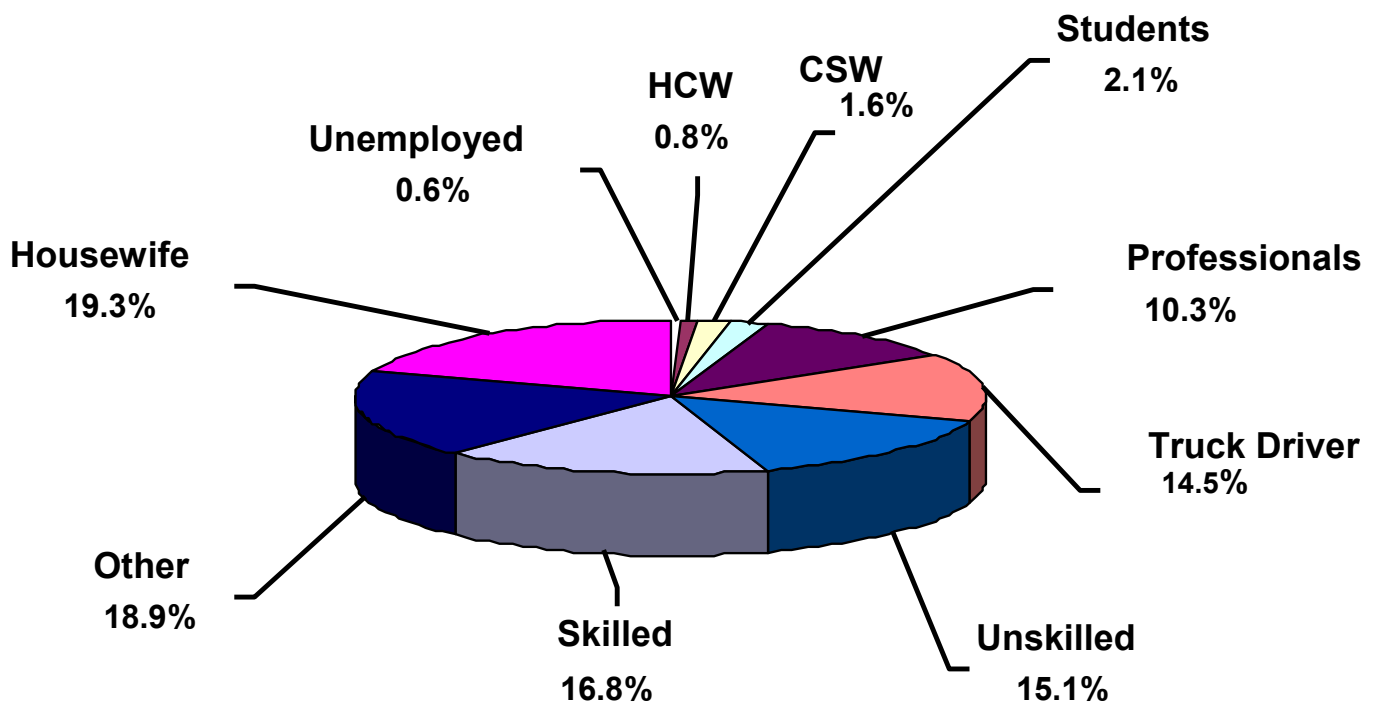

\subsubsection{Medical care}

Medical care at YRG CARE started at a crucial time, when there were few people who treated the disease in the country. In the beginning, the medical care program started in a partitioned room in the administrative office with the help of one volunteer doctor. As explained already, there was initially considerable opposition from the landlords and the neighbors in the area, but this was overcome by inviting them to the premises and demonstrating the safety measures adopted, for example, in disposal of syringes and needles.

YRG CARE began its regular clinic services at one of the mission hospitals, which provided one room to admit the patients, with outpatient care that functioned twice a week. With an increasing patient load, a house was rented in the suburbs of Chennai to take over this function. Owing to the inconveniences of distance and other problems for the patients in accessing care, the director of YRG CARE approached the Voluntary Health Services, which operated a multi-specialty hospital, to request space for admitting and treating PLHA. YRG CARE was given access to an abandoned leprosy building on the campus of VHS, and with the help of the Rotary Club and the Round Table (a grouping of businessmen), the building was renovated to start a full-fledged hospital for HIVIAIDS in December 1996.

The medical care services offered by YRG CARE are outpatient care, day care, in-patient care, home care, and care through specialists by referral. Four full-time doctors, five nurses, and three paramedics operate the facilities. The outpatients are able to access medical, psychosocial, and nutritional advice. The focus in outpatient care is preventing and treating opportunistic illness. If the patient can afford it, antiretroviral therapy is also available. 
Since it was founded, YRG CARE has paid great attention to the quality of care it provides, and how quality will be monitored and maintained. They follow guidelines developed by the government of India and by others, including WHO. ${ }^{21}$ In fact, in 1998 the director of YRG CARE, Dr. Suniti Solomon, participated as a reviewer of new Government of India/NACO guidelines for HIVIAIDS care and support. In 2000, YRG CARE produced two publications relating to quality of care, the HIV Colour Guide, and a companion piece entitled Treatment Guidelines. $^{22}$

The experience and expertise of Dr. Suniti and the YRG CARE medical and support team in providing good quality care and support services have been recognized by the Government of India/NACO, WHO, UNAIDS and others. Abstracts and papers about YRG CARE's services and clinical experiences authored by Dr. Suniti and her team are often selected for presentation at international meetings and conferences. Four YRG CARE staff were selected to present papers at the Second International Conference on Prevention of HIV Transmission from Mothers to Infants in Montreal, Quebec, 1999. On top of these presentations, YRG CARE expertise is also partly reflected through more than 70articles that have been accepted for publication in peer-reviewed journals. ${ }^{23}$

Although recognition of YRG CARE's expertise in providing quality care and support is important, staff understand that this must translate into vigilant adherence to standards of care that are consistently delivered to all patients. This begins with a rigorous orientation for all new clinical and counseling staff lasting three months, and the training period for nursing staff lasts for six months. Clinic staff do not prescribe medications until after the orientation period, and all new staff are closely supervised, observed, and supported through training and partnering with more experienced staff. Beyond orientation, YRG CARE's director, senior medical officer, and other senior staff undertake periodic spot checks for quality control purposes. Periodic case reviews are conducted to share common challenges and appropriate responses. Clinical staff regularly consult written treatment and care protocols based on the standards of care guidelines referenced previously.

An ongoing program of continuing education, staff development, and access to practical and up-to-date information underpins all of this supervision and close monitoring. This effort is not confined to YRG CARE itself, but is extended to other care providers. Since 1996, YRG CARE has produced a periodic publication called Wrap- $U p^{24}$ that summarizes new developments in HIVIAIDS care and support relevant to the Indian context. Wrap-Up is distributed to 3,000 physicians and other care providers in South India, and receives funding from the Australian Agency for International Development (AUSAID) in New Delhi.

\footnotetext{
${ }^{21}$ Care and support guidelines and reference texts used by YRG CARE include: Guidelines for the clinical management of HIV infection in adults, WHO, Geneva, 1991; Guidelines for the clinical management of HIV infection in children, WHO, Geneva, 1994; AIDS home care handbook, WHO, Geneva, 1993; and The Sanford Guide to HIVIAIDS Therapy, Jay P. Sanford et al, USA, $7^{\text {th }}$ edition, 1998.

22 Solomon, S. and colleagues, HIV Disease in India: a colour guide, 2000, East West Books (Madras), 117 pages; and Gaitonde, V. (editor), Treatment guidelines, 2000, East West Books (Madras), 101 pages

${ }^{23}$ A full bibliographic reference is available upon request. Examples of articles include: "Ophthalmic manifestations of Human Immuno-deficiency Virus (HIV) infection in India," Indian Journal of Ophthalmology, Jyotirmay Biswas et al, 1999, no. 47, pages 87-93; "Prevalence and risk factors of HIV-1 and HIV-2 infection in urban and rural areas in Tamil Nadu, India," International Journal of STD \& AIDS, Suniti Solomon et. al., 1998, no. 9, pages 98-103.

${ }^{24}$ Back issues of Wrap-Up are available upon request.
} 


\subsubsection{Initial examination and diagnosis}

The physician examines the patient, detecting diseases and deciding on any treatment that is required. If the patient requires examination by a specialist, he or she is referred to the centre of the required specialty. Since December 1995, YRG CARE has successfully operated a consortium of consultants based at some of the premier specialty institutions in the city of Chennai, where patients can be referred.

\subsubsection{Outpatient care}

The outpatient care unit operates from 10:00 am to 3:00 p.m. Monday to Saturday in the YRG CARE medical center on the VHS campus. Patients come by appointment or walk-in for consultation on HIVIAIDS-related ailments. Female patients are directed to the Women's Clinic, and the children are referred to the pediatric care facility. For the one-year period between September 1999 and August 2000, YRG CARE logged 3,420 outpatient visits.

\subsubsection{Day care}

The day care department operates from 10:00 am to 3:00 p.m. Monday to Saturday. On average, 10 to 20 patients per month use the services per month for routine day care, including for routine medical check-up, infusions, injections, dressings, investigations, counseling, and nutritional assessment. The patients also receive a free dental check-up from Raagas Dental Clinic, which operates a clinic at the day care centre. In addition, a childcare clinic is operated once a month on a specified Sunday. The patients are informed of the date of the presence of the pediatrician during their first visit. The day care service was utilized 102 times during the year from September 1999 to August 2000.

\subsubsection{Inpatient care}

There are 24 beds for men, women and children at the medical centre. In addition, there are three private rooms in the main block of VHS. Acutely ill patients with complications of opportunistic infections (PCP, severe gastroenteritis, CMV retinitis, tuberculosis, crypto, toxoplasmosis, meningitis, etc.), who need intensive care are admitted and treated. Spiritual counseling is also made available for those who request it (approximately 10 to 15 patients utilize this service at a time). Patients stay in the hospital until they feel better, and are charged based on a sliding scale according to what they can afford to pay. A total of 2,830 bed-days were tallied for the period between September 1999 and August 2000.

\subsubsection{The Women's Clinic}

Women with HIVIAIDS who come to the centre are directed to the Women's Clinic, where a female doctor examines them. The examination begins informally, with the doctor initiating a general dialogue about health. The patient's sexual history is taken, and issues related to personal hygiene, menstrual cycles, reproductive tract infection, reproductive health, sexual health, sexual practice, and safer sex are discussed. Modes of HIVIAIDS transmission and prevention are reviewed.

If the patient is pregnant, information regarding safer modes of delivery is elaborated. Antenatal, intrapartum, and postpartum care are explained. During the discussions, confidentiality and breastfeeding often crop up, and common myths and misconceptions are clarified. If it is found that there is a problem in the partners' relationship, the partner is asked to come for a discussion. The service is much in demand, and women often return with their spouses for further advice. Depending on need, the use of condoms is demonstrated to the couple. 


\subsubsection{Pediatric care}

Until the end of 2000, this service operated once a month with the help of a pediatrician who visits the medical centre from Mysore; however a consultant pediatrician from VHS is now handling this service. Pediatric care is usually outpatient care, and if the children are acutely ill they are admitted in the centre and followed-up by the physicians of YRG CARE.

\subsubsection{Home care}

Home care is an integral part of the ideal continuum of care model, as part of psychosocial support and medical care. The service, in operation since 1994, supports terminally ill people, pregnant women, and very important people (VIPs). A senior nurse undertakes the visits, and doctors visit when necessary. Patients are visited at home as friends, without any sort of such formalities as uniforms, in order to guard the confidentiality of the patient.

A radius of 30 kilometers from the hospital is covered under the home care service. Patients are followed on demand or by a routine, as needed. Treatment advice, counseling, nutritional advice, and monitoring of the current health condition are some of the issues covered during the visit. Confidentiality is strictly observed. Patients are charged according to the distance that must be traveled, apart from a nominal fee of $100 \mathrm{Rs}$. An estimated 208 home care visits occurred during the period from September 1999 through August 2000.

\subsubsection{Referral}

The importance of a client-centered service is evident through the network that YRG CARE has built up over the years with specialty hospitals, NGOs, doctors, individuals, and other institutions. This service started with motivating the doctors of prestigious specialty centers in the city who were willing to offer assistance in the care for the PLHA. The aim of the service is to ensure adequate treatment for all patients depending on their need.

YRG CARE networks with Sankara Nethralaya for ophthalmology and diagnostic care; Voluntary Health Services for neurology; Rigid Hospital for gastrointestinal, obstetrics and gynecology care; and CSI Rainy Hospital for obstetrics and gynecology care. Referrals are made to individual doctor for dermatology and pediatric care. NGOs and community-based organizations offer services in short stay homes, providing food and clothing to PLHA. YRG CARE places great importance on ensuring that PLHA will always have somewhere to go for treatment, and building and maintaining a viable referral network helps ensure that this critical objective is met.

\subsection{Other services and activities}

\subsubsection{Support services}

The support services offered by YRG CARE consist of legal assistance, education, employment, insurance, and more. These services are offered with the help of professionals who volunteer to support PLHA. 


\subsubsection{Policy, advocacy, and networking}

YRG CARE invests considerable effort in participating in state, national, and international meetings and conferences to influence the adoption of more appropriate policies relating to prevention, care, and support for PLHA. Advocacy for the rights of PLHA is supported by the statistics and experiences of YRG CARE and the ongoing clinical and social research that it conducts. YRG CARE is also an active member of NET WORKS, a group of 15 NGOs working to prevent the spread of HIVIAIDS in India and Nepal, supported by the Ford Foundation. These organizations work with many diverse constituencies, including the rural and urban poor, the middle class, truckers, people working in prostitution, drug users, blood donors, men who have sex with men, non-literates, adolescents, community groups, health providers, the military, and police. ${ }^{25}$

\subsubsection{Training and support services offered}

Through the experience gained in dealing with PLHA, as well as in the area of prevention, YRG CARE has become an important source of professional training on HIVIAIDS and related fields. Training is provided to other trainers, doctors, and paramedics, within the government, NGO, and private sectors. In-house training is offered for university students from India and abroad, and for professionals to get a first-hand experience of working with PLHA.

In recent years, YRG CARE has increased the training and capacity-building activities it provides, such as those it conducts with Horizons and the International HIVIAIDS Alliance to scale-up care and support services at four sites in South India. Through this project, for example, YRG CARE works with partners to identify needs, and then organizes training workshops, mentoring, exchange visits with other organizations, or on-site visits at YRG CARE, depending on what is most appropriate. Topics covered are wide ranging, covering such organizational development subjects as proposal writing, resource mobilization, and project management, as well as technical issues relating to HIVIAIDS treatment and care.

\subsubsection{Staff development and continuing education at YRG CARE}

Depending on staff experience and capacity, special training is organized. ${ }^{26}$ Experts and professionals in different fields do the training, or else staff development is supported through attendance at external meetings, conferences, and other skills-building opportunities, both inside and outside the country. Dissemination of the latest information on HIVIAIDS takes place during regular meetings and discussions, and helps the staff keep abreast of the latest developments in the field of care and support.

\subsubsection{Publications and research}

YRG CARE has a long list of more than 40 publications to its credit on a diverse range of topics related to HIVIAIDS (available upon request), developed in response to a recognition that there is a severe lack of information about the disease within the India context.

Realizing the need for context-based information, meticulous effort has gone into documenting the medical problems of PLHA who have visited YRG CARE.

As already mentioned, YRG CARE disseminates a quarterly newsletter to health workers called Wrap-Up, with 3,000 copies circulated to universities, physicians, academic and research institutions, NGOs, donors, and individuals who show special interest in the field. The organization has also produced numerous educational and training materials.

${ }^{25}$ YRG CARE organizational brochure.

${ }^{26}$ See also section 2, Medical care, covering the assurance of quality of care within YRG CARE. 
The organization is involved in numerous research projects, sometimes in collaboration with other national and international organizations. Research findings have been presented worldwide and published in national and international journals.

\subsubsection{Resource mobilization and sustainability}

Prevention programs at YRG CARE have been successful in attracting donor funding, notably from the Ford Foundation, which provided the very first grant for the organization's work. YRG CARE also carries out a limited number of programs in industrial settings for a fee, paid by the employer. Consistent with what has been observed in other developing counties, YRG CARE has found that donors are much more willing to provide funds for prevention work than for care and support, and this has been a constant challenge.

YRG CARE has recognized the importance of developing and sustaining a diverse source of resources. This is not limited to financial contributions but also includes donated materials, drugs, the donated time of medical specialist and volunteers, and other in-kind contributions. In-kind support mobilized by YRG CARE has been extremely important in enabling the organization to expand and sustain the care and support services it provides.

From 1994 to1997, requests from YRG CARE for support from established donor agencies yielded no results. Most donor agencies viewed the area of care and support as a "bottomless sea" and restricted their support only to prevention activities. However, in 1997, the Australian Agency for International Development (AUSAID) provided a small grant in support of YRG CARE's medical center. YRG CARE received a second grant from AUSAID in 1998, yet owing to a shift in their funding priorities (they moved to support programs in the North East), there was no further support forthcoming from this agency after that time. In 1999, the Levis Strauss Foundation in the United States provided a small US $\$ 15,000$ grant to partially support the activities of the medical center.

Until 1997, YRG CARE met its infrastructure needs from donations from local Rotary Clubs, Round Tables, and other community social action groups. In return, YRG CARE offered a number of public education workshops and was featured in community discussion forums. YRG CARE discovered that individuals were more forthcoming about supporting their work when there was an appeal on an empathetic level, rather than at an organizational level. Another strategy that facilitated contributions by individuals for care and support work was that YRG CARE worked out a per-patient day cost of care, which currently stands at Rs. 1,092 per week or approximately US $\$ 4.00$ a day. Clearly delineating these costs helped mobilize a number of philanthropic individuals, who then expanded their support through inkind donations (e.g., a television, linen, drugs, food for patients and families on visits, etc.). The Rotary District donated a three-wheeler "auto-rickshaw" in support of the home care team.

An important strength of YRG CARE has always been its investment in networking. Reliable partners have emerged from the process of networking. For example, the VHS hospital provided an unused leprosy building to YRG CARE that was renovated and rebuilt into its medical center, today a 24-bed facility. Also through networking, YRG CARE facilitated the formation of a "consortium of consultants" comprised of eminent physicians and surgeons in the city. These consultants donate their valuable time and services to patients referred by YRG CARE. Some of these consultants were part of large institutions (e.g., an ophthalmic care and research facility, and a dental health teaching institution). This occurred at a time when most hospitals in the city were still actively discriminating against those living with HIV. Similarly, a team of volunteers comprised mostly of young adults began to provide support services for patients accessing YRG CARE for services. 
The importance of donor support cannot be discounted. Although many may view 100 percent user fee cost-recovery as optimal, the reality of patients with disadvantaged economic backgrounds necessitates supplementary grants for maintaining and building care and support services. The grant from AUSAID provided the stability for YRG CARE to recruit full-time medical personnel. It enabled YRG CARE to begin clinical research in association with U.S. universities, notably Brown University, which also meant that patients would gain access to diagnostic tests as well as drugs for common opportunistic infections. These projects also support staff salaries.

Serving our patients better is the priority that underpins all research projects that YRG CARE engages in. An Institutional Review Board scrutinizes all research projects for participant safety, and YRG CARE does not undertake the testing of experimental drugs, devices, or procedures on patients.

One of the key strategies of financial management at YRG CARE is described as "recouping of resources." As a non-profit organization, YRG CARE is committed to providing free services to those in need. However, since HIV affects individuals from a range of economic backgrounds, it has established a user fee system. This system applies the principle of "adequate pricing." A sliding scale allows concessions and waivers to be made in line with the financial status of a patient (established through a financial counseling session). Services, laboratory tests, drugs, and other support are assigned costs based on the sliding scale.

Drugs do not include antiretrovirals, except in cases where the patient can afford it. However, YRG CARE is among the very few agencies in India to provide antiretroviral prophylaxis to prevent mother-to-child transmission of HIV. In 1997, YRG CARE established a patient care fund, with local donations qualifying for tax deductions, and visitors to the medical center often provide donations to this fund. The fund is operated as a revolving fund to support the deficits from the application of the sliding scale, for purchase of antiretroviral drugs and infant formula. Since YRG CARE does not as yet have an operating theatre for delivery of pregnant women living with HIV, it hires operating theatres from other hospitals. When patients cannot afford to meet these costs, the fund would support them. A consultant obstetrician-gynecologist and other support staff perform pro bono work for such patients.

Finally, the YRG CARE medical center offers training and hands-on experience for physicians in HIV management, offered at a cost of Rs. 5,000 for a five-day period. Students from international universities also undertake elective placements at YRG CARE and pay a small U.S. dollar fee for overheads and the costs of time of the medical personnel attending to their training needs.

\subsubsection{Project development and management}

YRG CARE conceptualizes and manages the work that it conducts into four project areas: service projects, training/scaling-up projects, research projects, and strategic projects. ${ }^{27}$ Service projects represent the backbone of the organization's work and include the provision of prevention education and sensitization on HIVIAIDS and other STIs, sexuality, and reproductive health, as well as other ongoing public education programs. The integrated continuum of care and support services also falls into this category, including voluntary counseling and testing, medical and psychosocial care and support (inclusive of day care, inpatient services and home care), and other ongoing support services for PLHA and their families.

${ }^{27}$ From the YRG CARE proposal to the GAP Foundation, page 2. 
The second area, training/scale-up projects, covers the training that is provided to others by YRG CARE. A number of activities are clustered into this category, including training on prevention, care and support, and scaling-up, to community groups, adolescents and youth, PLHA, health professionals, HIVIAIDS service providers, the media, and police. Efforts to document and disseminate lessons learned to others also fall into this category, such as the HIV Colour Guide and HIV Treatment Guidelines.

As is evident from the title of the third area, the research projects category comprises all of the research activities undertaken by YRG CARE, including those it does on its own or in collaboration with others, such as Brown University, Fogarty International, Johns Hopkins University, the University of California at, San Francisco, and the Horizons Program/Population Council.

The final area, strategic projects, are projects viewed as pilots, new ventures, or one-off activities for the organization, which may or may not eventually become fully integrated into the mainstream work of YRG CARE as a service project. Examples are the organization's work on HIV education in prisons, among the police and armed forces, and others. 


\section{References}

Gaitonde, V., ed. 2000. Treatment guidelines. Madras: East West Books.

Horizons Program. 1999. Scaling up affordable and appropriate care and support services for people living with HIVIAIDS in South India (proposal).

Mani, I., J.L. Franklin, A.K. Ganesh, and S. Suniti. 2000. Reaching rural Tamil Nadu through art forms: a pilot study by YRG CARE, [ThPeD5679]. Presented at the XIIIth International AIDS Conference, Durban, South Africa.

Rajan, Rashmi Pachauri. 1992. Pragnya: from consciousness to awareness. Madras: AIDS Resource Group of Madras Medical College.

Scott, A. and Bailey, M. 1997. Trip report, International HIVIAIDS Alliance. 1997.

Solomon, S. 2000. AIDS: frequently asked questions. Madras: Rekha Books.

Solomon, S. 1998. Dances of the sunflower. Chennai: YRG CARE.

Solomon, S. et al. 2000. HIV Disease in India: a colour guide. Madras: East West Books.

Solomon, S. et al. No date. Let us talk about HIVIAIDS (set of 24 slides and discussion guide). Chennai: YRG CARE.

Solomon, S., with Rashmi P. Rajan. 1997. Whispers from within: the unheard voices of HIVIAIDS. Chennai: YRG CARE.

Thamburaj, J. Easter, S.K. Satish Kumar, A. Edwin, A.K. Ganesh, and S. Suniti. 2000. Students' perspective on sex education: a comparative study from Chennai, India, [ThPeD5595]. Presented at the XIIIth International AIDS Conference, Durban, South Africa.

YRG CARE. 1996. Learning to play safe. Chennai.

YRG CARE. 1999. Body beautiful: a women's reproductive health manual. Chennai.

YRG CARE. 1999. Encounters that help. Chennai. 